\title{
AN APPEAL TO THE CONSCIENCE OF THE AFGHAN EXPATRIATE COMMUNITY FOR THE SURVIVAL OF AFGHANISTAN
}

by Michael Morgenstern

\section{The Forgotten Tragedy- A Millennial Culture Struggles To Survive}

With the Kosovo, Bosnia and Iraque and other politically more important world trouble spots dominating the headlines in the last few months and even years, most people are unaware that there has been smouldering another civil conflict and humanitarian catastrophe in far-away Afghanistan.

That tragedy has produced many more dead than Bosnia, many more refugees than Kosovo and much more destruction than both these conflicts combined, yet even when the bombs and rockets where exploding in Kabul, the capital, the world hardly took notice. Attending to the injured, the maimed, the hungry and the uprooted was left to the United Nations humanitarian missions, the Red Cross and the many international NGOs through which Western governments showed a modicum of concern and succour towards the suffering of the ifghan people.

Il srems that in the post-cold-war-era not only is there a diminished level of identification with the plight of a people that managed to shake off the yoke of communism by defeating the mighty Red Army ten vears ago, but it also seems as if powerful international interests (1) not wish to see ended the self-destructive civil conflict that crupted among the victorious "mujahideen" factions shortly after Kabul fell. Every time that a negotiated end to the war seems within reach, outside pressure upon one or the other faction result in he resumption of the fighting. As if to hammer home the futility of any further peace making efforts, even by traditionally Afghan-friendly countries, such as Germany, the latest and probably last UNsponsored peace mission in Afghanistan in which Afghans have placed any hope, that of the German diplomat Dr. Erwin Holl, as Special Representative of the Secretary General of the United Nations, was never even allowed to gain any momentum. Financial and political support from both the US and his own country were lacking from he start.

Simultaneously, the world's humanitarian commitment to Afghanistan is also waning. The UN has recently launched its annual appeal for that war-ravished, impoverished country, asking the world's governments for 112 million dollars in priority humanitarian assistance. That is not much for a nation of twenty-five million people, that in the course of the last twenty-five years have been deprived of all the qualities of human existence that people in Europe and North America consider essential for the pursuit of "life, liberty and happiness". The contributions actually received by the various UN organisations, the Red Cross (ICRC) and the NGOs for attending the most urgent of humanitarian needs arising out of the war and for meeting basic survival needs of the Afghan population, will probably follow the tendency of previous years and reach not even $50 \%$ of the amount of aid requested.

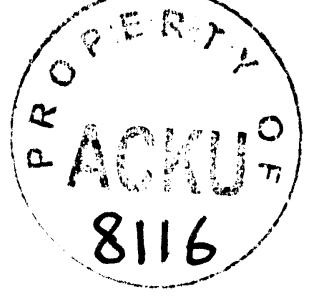


tendency of previous years and reach not even $50 \%$ of the amount of aid requested.

While in per capita terms the amount of aid given to Afghanistan has always been very small, especially when compared with that given to other countries in conflict, such as Cambodia, Bosnia, Palestine or the Congo, which elicit a greater geopolitical interest, the international commitment to Afghanistan has actually been dropping rapidly in the last few years. While the UN appeal for 1996 still called for contributions in excess of $\$ 200$ million, including almost $\$ 100$ million for food aid related activities, that for 1997 proposed expenditures of only $\$ 107$ million and for 1998 of only $\$ 104$ million. At first glance the amount of humanitarian aid requested for this year appears to have risen by about ten percent, but this is an optical illusion. Previously NGO, ICRC and bilateral contributions were not, or only partially, included in the final figure of this UN-prepared appeal; now most funding requests from all sources for Afghanistan, even those unrelated to UN activities, are included. When compared on the basis of the same accounting standard as that used in 1996, then the amount requested for 1999 , including $\$ 10$ million directly related to alleviating the suffering and the damage caused by two devastating earthquakes which struck the North of Afghanistan last year, is only about $\$ 70$ million, or $65 \%$ less than in 1996. Of that amount $\$ 25$ million alone is earmarked for the expensive demining effort, an exercise in futility which will be barely sufficient for clearing 50 square kilometres of the 5000 square kilometres catalogued as mine infested. Except for the food aid provided by the World Food Programme, which has also been cut by more than $50 \%$ over the last three years, and the salaries of local staff, most of the funds are used to pay for international staff who live outside of the country.

If this negative international funding tendency continues, and this must be taken as a given, then the international community's humanitarian contribution to the people of Afghanistan will soon consist of little more than the high-risk employment opportunities that the UN demining programme offers. The amount of international funding directly accruing in benefit of the Afghan people will soon dwindle to an amount that is insufficient to maintain even the most essential emergency aid intervention structure, which is vital, considering that public services are inexistent. The current level of international aid granted to Afghanistan constitutes little more than a palliative and a moral alibi for the international community. Here we have much more than another case of "donors' fatigue", instead, the world is not really politically committed to resolving the Afghan conflict.

The marginalisation of Afghanistan is blamed upon "antidemocratic" and retrograde policies of the "Taleban", the strongest opposition rorce, which occupies the capital city Kabul since 1996. However, this rundamentalist group was assisted and abetted by the US government and US economic interests that wanted to build an oil and gas pipeline across Afghan territory. This "student militia" has managed what no UN peace diplomacy was able to achieve before this group' appearance: unite all the previously warring factions into one coalition government, albeit now with very little remaining territory. 
It cannot be denied that since the Taleban have come to power some semblance of order has returned to the country.

With its infrastructure almost totally destroyed, with most of its leadership, its intellectuals, its professionals and persons of means having left the country, the remaining, poverty-stricken population now suffers continuous food shortages, lack of shelter in the face of harsh winters and little, if any, employment opportunities. Its young people, the heirs of a proud, millennial tribal culture that has permitted their ancestors to survive against all the odds which a barren and unkind natural habitat and the continuous threat of imperialistic neighbours and transiting armies has confronted them with, have largely forsaken these traditions. They have instead shifted loyalties from their elders to local warlords, who in turn, have rewarded them with the material benefits and the respect that goes with carrying a gun. Unwittingly and for lack of other economic alternatives, these masses of uneducated, decultured youths and their equally misled "commanders" are contributing to the destruction of the delicate traditional thread which has held their society together, even in these times of hardship. Survival of its individual members is threatened by war, famine and disease. In the face of continuous deprivations, anarchy, recurrent natural disasters and warfare Afghanistan has survived because of the strength of its solidarity culture and not because of any special assistance efforts of the international community. When a new generation devoid of cultural, traditional and religious values takes over and falls prey to the enticements of today's degenerate Western culture, that traditional resilience will be dealt the final blow. When, if, that happens, then Afghanistan will be conquered more thoroughly and more lastingly than during the Soviet occupation.

\section{The New World Order Has No Room for Sovereign, Self-Determined} States

The resilience, stamina and capacity for survival of the Afghan people has astounded the world and has brought it much sympathy from individuals, private groups and some governments guided by humanitarian concerns, but these have little weight when judged against the dominant geopolitical will of the predominant internationalist forces that today determine the largely homogeneous priorities, policies and actions of the so-called "international community". Unfortunately, the individual voices in the concert of nations are not those of sovereign and free peoples anymore, to whom Afghans could turn for well-meaning assistance; the "new world order" $^{n}$ operative today makes it economically, diplomatically and politically very difficult and potentially expensive for any country to pursue policies or national interests that are not in accordance with the "internationalist party line", which is then disseminated as democratically relevant and politically correct public opinion throughout the world's media.

When wittingly or unwittingly the people in Europe and North America are being led into a new crusade against the Moslem world, then the 
real target are those few culturally and religiously strong countries that still dare to act as sovereign and independent nations in the defence of their national interests, their culture and of the God-given right of their peoples to pursue life, liberty and happiness as distinct and precious components of the human race. It would be naive to suppose that one of the most fervently Moslem and fiercely independent peoples in the world, which has demonstrated unprecedented strength in their defence against powerful internal and external enemies and which could eventually become one of the most respected and influential countries of the region, should expect nurturing support from the same forces that will violently oppose any assertion of independent and sovereign national interest anywhere in the world.

What better way, than to clandestinely foster the perpetual continuation of internal strife that paralyses the country and allows the self-destructive internal forces to render it helpless to repulse open or covert aggression, when the enemies of an independent, strong and sovereign Afghanistan find it convenient and safe to do so again.

A demonstration of what is in store for Afghanistan under the "new world order", under the guise of moral justice, human rights, freedom or international law, was the recent totally unprovoked and illegal US incursion into Afghan air space, in order to drop bombs on innocent people for supposedly sheltering "international terrorists". Hardly any member of the "international community" condemned this cowardly act of brutality by the "world policeman" and -what is worse- the Afghan national and expatriate voices could not be heard in protest. Such "punitive" incursions have become a standard instrument of post-cold war US power politics and Afghanistan will remain an easy, low-risk target while this still free country is unable to defend itself.

\section{The Brave New World of the "New World Order"}

The State of Afghanistan is today one of the few remaining independent and truly sovereign countries, as yet untouched by the hidden hand of the global players. The mega-imperialists that dominate the cultural, economical and political affairs of practically all the countries of the world have not yet gained a foothold in this cultural gem among nations, that was once the cradle of European civilisation. Yes, different neighbouring countries are trying to exert influence over the various belligerent factions at the behest of their international masters, while Afghan national authority remains inoperational, but the Afghan State can at any time when internal conditions permit reassert itself, without any restrictions to its sovereignty and its free national will. As such, Afghanistan, although presently agonising and feeble, constitutes a bulwark against the antinational, imperialistic designs of the globalists, an unholy alliance of savage capitalists and "cultural communists" that dominate the course of world affairs today. These new super-imperalists have destroyed sovereignty and national ethnic cultures wherever their financial, political and cultural tentacles have reached. It is in their 
vision that under the new world order there will be no more nation states and no more ethnically divergent peoples that can rally around a common culture, religion, or leader.

Instead, there would only be two main classes of world citizens: a superrich, economically omnipotent, ruling international elite and the world's remaining disenfranchised population, devoid of "dangerous" affiliations, such as nationality, clan, family, culture and religion. This "new proletariat" will be culturally brainwashed (i.e. educated) to believe that they are living in the best of all possible "democratic" worlds, but in reality would be totally exploited, living in abject poverty, and serving merely as cheap labour force and consumers of the gadgets the international economic power elite has determined to sell to them. The individual citizen, whether living in the poor or currently wealthy regions of the world, will have been deprived of their jobs, their businesses, their money and their remaining possessions by recurrent, apparently unavoidable economic crises, devaluations, inflation and wars. Even the last possession of many impoverished peoples, their cultural values, their traditions and their glorious histories, are to be eliminated from their collective memories, while they are deprived of the guidance of patriotic leaders, of the protection of a nationally committed government, of the unifying power of their ethnic group and of the moral strength of their religious faiths. Indeed, when the globalists' "multi-cultural" plans have been achieved, the ideals of the French revolution, "egalite", "fraternite" and "humanite", which were the cornerstones of democratic thinking, will take on a more perverted and macabre meaning than was ever the case during the heyday of Stalinism. In fact. the designs of the savagely capitalistic proponents of a oneworld government look like totalitarian communism with a vengeance, but by another name; a one world-wide Soviet Union without its rederming humanistic grace.

The most frightful part of this internationlist vision are the clandestine demographic policies of this world government in formation. Six billion hungry and recurringly rebellious slaves would be an unnecessary burden on the resources of the globalist elite and the economic/financial conglomerates which will be the principal employers of the remaining "productive" labour. The "culling" process which has been operational in the third world for some time, is now already affecting the so-called "richer" countries of the Western world, where millions of workers are being sent into unemployment every year without miserocordia by the multinational conglomerates. In accordance with their plans the world population would have to be reduced to a more manageable and economically justifying number of brainwashed (Hollywood "entertainment" and Murdoch satellite TV) automatons without cultural, religious and national affinity and strengths of their own. Inter-ethnic warfare, disease, starvation, "natural" catastrophes and ecological disasters, in addition to such "democratic values" as the encouragement or condonement of abortion and sterilisation, homosexuality and corrupted morals, drugs, "women's liberation", pornography and uncontrolled crime can easily be utilised as additional "demographic regulators" and "conditioners", as well as a way to rapidly destroy the social fabric of any society. 
This has worked to perfection in many countries, but started out experimentally in Germany after the second world war. Here we have a country which not so long ago was as sovereign and militantly independent a nation as Afghanistan, with all its anarchy and selfdestruction, remains to this day. She was considered a model of the occidental world, where the arts, science and / the highest values of human civilisation flourished. Now that country has dropped to an abysmal level of societal irresponsibility, that of a sorry vassal nation without values and self-esteem, without honour, without morals and without shame, unable and unwilling to defend itself even in the face of permanent attacks that threaten its very national existence. If this cvil design worked so well in Germany within the short time span of two generations, then it will work in Afghanistan, or anywhere else. In Afghanistan this subversive agenda had to be suspended for twenty years in view of the inability of the global masters to direct developments from the inside through easily influencable "democratic institutions", a subservient press and revolutionary "agents of change". The old strategy of "divide and conquer" had to be used instead and found very fertile ground. Afghans, and especially expatriate Afghans, should wake up, overcome their parochial differences and, while they still have any fighting strength left, save their country, their peoples, their cultures from eventual destruction. In the process they could be a beacon of human liberty, national rights and hope for other countries, peoples and patriotic groups that are struggling to resist this sinister plan for a world devoid of nations, devoid of cultures and devoid of all "unproductive" people with nothing left to be economically exploited.

Under these circumstances it is futile and even dangerous for Afghans to pin their hope for an end to the internal conflict upon the benevolent intervention and support of any supposedly "friendly" outside source. No significant country, with the possible exception of China and a diminishing number of Moslem states, will be able to counteract the manifested determination of the "international community", even where good will exists on a personal or bilateral basis. In the spirit of what the great Pan-German patriot and founder of the student athletic movement, "Friedrich Ludwig Jahn", said in the last century, when the German people's national aspirations were stifled by the internecine fighting and dynastic pretensions of princes and kings: "Only the Afghan can help the Afghan!"

The Vain Hope For An Internationally Brokered Peace SettlementMissed Opportunities For An Afghan Solution

Afghans should forget trying to find the solution to their national problem through international diplomatic or financial assistance. This modern day adaptation of the old "divide and conquer strategy" that has worked so well over the last ten years, always comes with strings attached and may put at risk whatever national solidarity still remains.

Afghans have the gift of being tenacious, daring and very adaptive when it comes to mastering difficult situations. This has helped them 
survive inside the country against all odds and has contributed to their success as businessmen wherever in the world they find themselves today. Most Afghan "capital", both human and economic, is today located outside of Afghanistan. Its intellectual, professional and entrepreneurial leadership must be involved in the peace process and being so dispersed throughout the world, they require a strong, patriotic representative organisation, beyond all ideological, religious and ethnic concerns. This is were the political initiative to save Afghanistan from its already programmed destruction should come from and this is also where the major part of the resources required for this task should come from. Unfortunately, all efforts to form a strong unified expatriate peace front in exile have failed when attempting to go beyond factional, ethnic or religious consensus and when it comes to finding financial sponsors for concrete actions.

An opportunity for a popularly supported peace project would have arisen in 1994, at the beginning of the Mistiri peace effort. At the time, this special representative of the Secretary General of the United Nations, who unfortunately never believed in the success of his own mission, was welcomed in the streets of Kabul, Herat, Kandahar, Jalalabad and Mazar like the saviour of the country, the long-awaited peacebringer, by a war-weary population, among whom there were a large proportion of flower bearing women. It would have encouraged Mistiri and the faction leaders he tried to bring together, if a committed group of Afghans in exile would have politically supported these efforts. If Afghan businessmen would have presented lucrative business proposals to key commanders in return for supporting an all party government, which the common people in all regions of the country clearly longed for, a solution to the conflict might have been found then.

Later, in 1995, when the Taleban were. still largely confined to the southern provinces and all factional forces were more or less in equilibrium in well defined geographic areas, it would have taken very little propagandistic effort to turn what was the beginning of a popular groundswell for a peace-making role of the exiled king, Zahid Shah, into an overpowering call for the return of the monarch to act as final arbiter in a conflict that was important only to a handful of mujahideen leaders and their "commanders". A few dollars well spent in targeted journalistic efforts and in coordinating appropriate street action, as well as in some strategic "golden handshakes", would have swayed the hold-outs among the opponents into accepting a mediative role of the king and would have taken the wind out of the sails of the Taleban.

Even as late as 1996, when a plan for gradual restoration of central authority was circulated that proposed the establishment of a unified customs collection system and of a national highway administration under temporary UN control, there would have been an opportunity for applying concerted expatriate lobbying power. After all, such an arrangement would have greatly benefited trade, transport and the resumption of some industrial activity, while actually preserving the power of the leadership when acting in concert, for the benefit of the nation. Such a scheme would have received a great boost if the expatriate business community had supported this, or a similar plan, 
with concrete investment proposals. Instead, only feeble and disconcerted efforts were forthcoming then.

(of course, now that the latest UN brokered peace efforts have failed again and the US has demonstrated that it is more likely to "donate" bombs than bread for Afghanistan's starving population, the prospects for an internationally-brokered political settlement are much dimmer. Even the most benevolent observers of the international community's policies towards Afghanistan must now realise that the country is artificially being kept from finding its own political solution. The overriding objective of the invisible world government's policies towards Afghanistan is its annihilation as a sovereign and free state and of its proud and strong solidarity culture. Its fiercely independent population could not easily be controlled by even the most ruthless "new world order" methods, such as those currently applied to Iraque and Serbia. This is why the Afghan conflict never ends, all international mediation efforts fail and less and less international resources are provided to keep the Afghan population (child mortality rate 200 per thousand live births) alive.

\section{Afghan Expatriate Commitment and Resources Are Called For - The Duplicity of International Aid}

The first step that concerned, patriotic expatriate Afghans should take in response to this threatening reality, is to launch an initiative for bringing peace, helping to establish a representative government and preserving the intrinsic strength of the country. This could best be done by organising a broad-based political organisation representative of all expatriate Afghans and obtaining the open consent, endorsement and, if possible, material support of those eminent religious, tribal or popular leader's that enjoy the respect of large parts of the population and that have not been politically compromised with one belligerent party or another. To be effective, such a group must have economic clout, i.e. it must have sizable endowments or significant financial support of wealthy members of the Afghan community. It should act as a national conscience and defend Afghanistan's national interests, as well as the Afghans' human rights. When one or the other side dropped bombs and rockets on the hapless population of Kabul, this should have been loudly condemned, as should have been the illegal US incursion. It is lamentable that Afghanistan today does not have one recognised national leader around whom all Afghans could rally and who could motivate even divergent factional interests to defend the Afghan people's legitimate, overriding national rights and interests. The exiled former king, Zahid Shah, would be such a personality, but he is now an old man and he was never allowed to play a decisive role in the UN-sponsored peace process.

As a second step, this group, which should demand a significant participation in any broad-based government to be formed, should be prepared to identify and negotiate private investment opportunities within Afghanistan of a type that all factions could support and guarantee, and to seek out relevant investment commitments from 
expatriate Afghan interests. Whenever there is support from all belligerent parties and whenever they stand to gain from such investments, these could be implemented even before there is a formal peace agreement. Indeed, the peace process could actually be furthered through such confidence building activities. It would also make it easier to activate the full reconstruction process after a broad-based national government has been established. The private resources that could be mobilised with such guarantees would be significant and the investments themselves could help overcome existing divisions among regions and groups. The more funds can be generated from expatriate sources, the less the newly formed AllAfghan government will have to resort to the international community for credit and financing, which always results in loss of sovereignty.

Some examples of initial investments which the expatriate community could fund with relatively little capital and limited need for international financing, could be:

1) maintenance of the country's deteriorating road network against the right to collect usage fees:

2) establishment of motor vehicle service centres along the principal highways:

3) scrap metal and valuable materials desmanteling, processing and recycling or smeltering;

1) industrial parks with own power supply and technical support facilities to encourage medium and larger scale enterprises;

$5)$ installation of wireless communication systems, including mobile phones, in strategic locations;

6) Fruit drying and processing plants

7) Forestry enterprises to combat mass employment and scarcity of wood

8) Factories for building materials and prefabricated building elements, made o local materials

9) Exploration of mineral resources

It has been estimated that more than 100 billion dollars of Afghanowned funds and investments are held outside the country, a large proportion supposedly related to illegal drug proceeds, others have originated from the "tax collection" powers exercised for years by individual commanders in the areas controlled by them. Another not insignificant component of Afghan foreign assets is the result of what the Pakistan government could consider to be "ill-begotten wealth from illegal transit and border trade". This makes a large part of Afghan wealth seizable under already existing international rules and banking laws, if at any time foreign governments or interests wish to place pressure upon Afghan individuals, groups or leaders. Repatriating a substantial part of these assets and redirecting them into joint ventures with private foreign investors inside Afghanistan would therefore appear to be not only patriotic, but prudent.

The reconstruction task ahead for Afghanistan is daunting, but without initiative from the side of expatriate businessmen and investors it is not likely to ever get started. To bank on the international community to provide resources for this task would be a mistake. The world will not break out into jubilation when a peace settlement is reached in Afghanistan, and so-called donor countries 
will not open their purses any more then, than they have in the past, despite the promises made when an end to the war was not in sight. Well rehearsed conditionalities will be heard again, such as "eradication of all poppy and cannabis production", "granting of equal rights to women and girls" or the extradition of "international terrorists". Whether justified or not, these and other demands will impede the major flow of international reconstruction funds that many Afghans, NGOs and UN agencies are hoping for. This should not necessarily be lamented, because once the UN, the World Bank, the $I M F$ and the financiers of London and New York are allowed to dominate the reconstruction and development process, the country will become economically and politically subservient to global interests attached to these, that are totally opposed to Afghanistan becoming a strong and actively sovereign country again. Practically all countries of the so-called third world have gradually lost control over their national resources and, with that, of their national destiny and even identity. They have been reduced to mere suppliers of cheap labour and easy wealth to profit-hungry transnational economic and financial interests.

Yet, Afghanistan's utter destruction and the need to start from ground zero, also provides the country with the chance to integrate radically new technological solutions into its reconstruction plans, since there are no major economic structures or interests left in the country that have particular rehabilitation strategies to defend. 
The Energy and Agriculture Sectors Offer Opportunities For Alternative Technology Solutions To Suppport The Reconstruction Process And Avoid International Endebtednes

The greatest source of dependence for most poor countries today resides in their need for energy and agricultural imports and the financial costs related to these. Some third world countries have to use all of their available foreign exchange earnings just to pay for these two essential items. Even relatively advanced and once proudly independent nations like Brazil, Mexico or Indonesia have had to sell most of their national patrimony for pennies on the dollar to foreign interests as part of so-called privatisation, structural adjustment or debt reduction programs. All of these will cause social and economic hardship for the affected country. "Foreign aid" and "emergency loans" will be graciously offered, but most of this international assistance will result in new financial obligations that will eventually require another round of "bail outs". These will then bind the country ever closer to international interests and will make the population even poorer. This trap has been laid for Afghanistan also, but the country need not fall into it.

There now exist technologies that could greatly reduce a country's dependence upon the international energy cartel and especially the petrochemical industry and their bankers. The established interests are vehemently fighting to preserve the status quo, but they will not be able to prevent that soon most energy will be produced decentrally from non-hydrocarbon sources that are cheap, clean and plentiful. In the future the main energy sources will be hydrogen, water (for combustion and implosion engines, as well as for vastly more efficient hydroelectric plants) and tachyons, sub-electronic particles that abound in the space around us. Engines powered by these fuels are running already and some are available commercially.

This presents a chance for Afghanistan to bypass much of the expensive current energy technology that may become obsolete before it is fully paid off. It may not be necessary, for example, to build large power stations or a country-wide electric grid, if low-cost electricity can soon be generated decentrally, or the output of existing hydroelectric plants can be augmented ten or a hundredfold with only limited engineering modifications to already existing plants. The power station at Sarobi alone could then possibly supply all the energy to meet the country's needs for years to come.

This power station modification is already available today. A German industrial group dedicated to new energy solutions is looking for sites where this experimental technology could be installed. They are even offering to finance the whole project and make further related investments that the country would require. Other alternative technologies that will shortly become available, are, among others: cold fusion reactors not much larger than a refrigerator that run on ionised hydrogen and which can produce enough electricity to meet the needs of a medium-sized community; bio-power generators for smaller requirements, such as for household use, for vehicles or for running irrigation pumps, that are operated by light-weight magnesium batteries recharged automatically by contact with water; 
night-active 500 watt solar panels that can extract four times the normal amount of energy from sunlight and which, in combination with special batteries, can produce directly the more convenient AC current: tachyon and infrared light powered home generating plants that will provide $90 \%$ of the energy requirements of the typical North American or European household for free; combustion engines that can run on water, as well as on crude oil, chemical waste or sewage; etc.

Such devices allow for the establishment of small businesses and essential public facilities even where connection to the electricity grid is not possible and fuel for powering combustion engines is not available. Their widespread use would save the country millions of dollars in oil imports. Investments in these futuristic technologies can make Afghanistan totally independent of imported fuels within a very short period and can foster the establishments of varied kinds of new industries in the country.

The next largest drain on its foreign exchange that reconstructing Afghanistan could expect to sustain would be for agricultural inputs. Being a mainly agrarian country, it will need to vastly expand its agricultural production in order to generate the foreign exchange to pay for the reconstruction process. Afghan fruits are among the finest in the world. The rehabilitation of the marvellous traditional irrigation systems found throughout the country will be expensive and time consuming and they will not be fully functional again until energy for the many idle pumping stations becomes available. If the country can resist the call of the petrochemical and the biotech industries and does not exchange traditional farming methods for the questionable benefits of artificial fertilisers and genetically manipulated seeds, then Afghan fruits will maintain their high reputation and market value internationally; the family or communal plot will continue to feed the population dependent upon it and the country will be spared the polluting and expensive chemical addiction, which eventually kills all agricultural activity, except that run by the big agro-industrial estates.

Newest studies in Germany have shown that bio-energetically treated quartz. sand sprinkled in minute quantities on the soil can produce the same or better harvest results than chemical fertilisers, without the cost and environmental damage and diminishing productivity that these entail. In most countries natural biological agriculture is not possible anymore because the soil has already become too degraded and contaminated from years of chemical fertiliser use and the permanent debts associated with high-tech production obligate the farmers to produce more and more at constantly decreasing returns. Afghanistan is in the favoured position of still having vast expanses of soil that have been untouched by the kind of suicidal agriculture that the petrochemical industry, as well as the research institutes and extension services supported by them, are pushing. Increasingly, many sophisticated markets, especially in Europe, are demanding organically grown produce from unaltered, genetically unmanipulated strains and are willing to pay top prizes for such difficult to find fruits and vegetables. Afghanistan should use this unique chance and develop its agriculture without mortgaging the future of its farmers 
and making them dependent upon expensive, contaminating inputs that will eventually cost more than the additional production that they may initially bring. Excessive deforestation over the last twenty years has caused more extreme weather conditions and has aggravated the problem of desertification in many parts of the country, but even here alternative technology solutions are available.

The most effective means to increase traditional agricultural production is to expand the areas under cultivation. Afghanistan's mineral rich lands only need water to turn even expanses of apparent dessert into gardens of Eden. A Swiss development that is able to produce periodic natural rain in desert and arid areas, even those normally deprived of rainfall. This method has already been used sucressfully in many countries but never has been given the official recognition that it deserves. It could be used in Afghanistan to permit rain-fed agriculture where irrigation canals do not reach and where crop production was not thought possible. Combined with the bio-energetic soil vitalisation treatment mentioned above and other rasily applicable natural methods, Afghanistan's agricultural production could easily be tripled without the use of expensive, harmful chemical fertilisers and genetically engineered seeds. The rain production technology is being sponsored by the same German kroup that also offers the hydroelectric plant modifications and here also payment is linked to successful performance, so that there would be no risk associated with such a project. Here we have another opportunity for generating hundreds of millions of dollars of additional agricultural income. This would also permit massive low-cost reforestation activities.

In terrain where agriculture is not appropriate, mining might generate equal or greater benefits. Although few studies exist about Afghanistan's mineral wealth potential, many experts and sporadic essays have pointed to vast deposits of different high quality ores, even at surface levels, permitting very low-cost mining with limited capital investment. A new very low cost, as yet highly secret technology for precisely locating and ectracting precious metals in microscopic particles as sludge from Precambrian meteoritic deposits is being applied with great success in Nevada and could be tried also in Afghanistan, where similar geological formations prevail. Should this be possible, then Afghanistan could become a net exporter of precious metals and some enterprising mining investors will become very rich in the process.

An alternative immediately applicable state of the art technology solution for producing gold, silver, platinum and other high value metals at even lower cost is available in Germany and could be particularly suited for Afghan investors. Electronic and industrial waste from damaged plants and buildings in Afghanistan or imported as industrial waste from neighbouring countries could be used as input for a recycling plant that produces noble metals and other valuable raw materials at $100 \%$ purity. Such factory could be considered equivalent to a franchise for producing gold and other precious materials from what industry and households normally throw away as refuse. Many Afghans are already in the business of buying and transporting scrap metal from the Central Asian countries to 
Pakistan for smeltering and could generate much more return if they had access to such a complex materials recycling plant.

These are a few examples of low-cost and mostly unknown cutting edge alternative technologies, that should be part of the Afghan reconstruction scene because they are low cost/high return investments for which pay-as-you-earn financing is available and which have the capacity of making Afghanistan independent of the World Bank, the IMF and other global financial interests that will seek to gain control over Afghanistan, as they have of other developing countries. With just a few of the investments mentioned, Afghanistan could easily earn or save more foreign exchange than she could ever hope to gain from foreign assistance under even the most favourable conditions.

Many Afghan benevolent NGOs have sprung up to help mitigate the consequences of the war and in order to act as implementing counterpart agencies for international aid providers. They have been able to compensate in some measure for the lack of public and private economic institutions. Often they are funded by expatriate sources and they should therefore play an important role in the proposed establishment of a supreme All-Afghan expatriate political and economic structure. These NGOs working inside of Afghanistan today harbour most of the country's remaining professionals and technicians. Some of these experienced staff would be excellent collaborators for the proposed alternative technology projects. The NGOs themselves in many cases could easily function as regular business enterprises and could be excellent local partners for expatriate investments. Others, that might be able to collaborate in socially oriented projects, have the capacity to attract large amounts of foreign contributions as matching funds for any resources which they themselves could be able to generate, Any expatriate investments made in partnership with NGOs could therefore often be easily multiplied. With these and other innovative, nationally funded approaches, Afghanistan could also set an example for other countries which wish to foster self-reliant reconstruction and development.

\section{Only Peace and Recovery Implemented Now by All Afghan Patriotic Elements Can Save Afghanistan}

However, in order to be effective and not have to contend with the kind of interference and conditionalities that come with international assistance, Afghanistan will have to take these pace-setting steps now. while the peace process is not yet concluded, lucrative investment opportunities abound and international community influence in the country is minimal. This is why the expatriate Afghan community with its resources, its professional experience and its patriotic commitment is called upon to act as the country's conscience, help establish minimally required national implementation structures and to start investing selectively again in their forgotten country. There are many business projects feasible that will benefit the country as a whole and which will strengthen Afghanistan's ability to defend itself against destructive internationalist forces 
that wish to see the country's potential national strength paralysed indefinitely.

It is not too late to save Afghanistan's national identity, its culture and its freedom, but Afghans must realise that while they continue to do violence to each other and to their country, they are doing the bidding of their real enemies. These are planning to subject them to another, more destructive form of marxist-leninist reality, designed and implemented by powerful multinational economic and financial interests that are invulnerable to kalashnikovs and self-propelled grenades. They pierce their target country's defences by economic and financial means, before taking over one national institution after another. They bet on the human frailties of elected "democratic" leaders and the gullibility of the masses, who, with the help of Hollywood propaganda, satellite TV and a "free" press, will readily forsake their traditional values that have made them strong and then become part of an easily controllable international proletariat.

Afghanistan can best protect itself by building its own economic base and avoiding to the extent possible all international debts, as well as conditioned aid. It should start now by undertaking projects that all parties in conflict can agree to, because they can benefit equitably from them. Afghan businessmen's special knowledge and negotiating acumen is called for in this situation, so as to be able to identify potentially lucrative projects with controllable risks that also foreign investment partners could accept. Most international and national conflicts revolve around economic issues, and this is no different in the Afghan situation. Enduring peace formulas are often also facilitated by economic solutions. The promise of receiving benefits from lucrative peacetime economic projects has often brought the breakthrough when other arguments failed. It would be better for Afghanistan as a sovereign self-determined nation, which it wishes to be again, that such offers come forth " now from Afghan sources, rather than later with strings attached from the multinationals behind whom stand interests which pursue anti-Afghan objectives.

No matter how the current, or future UN humanitarian appeal for Afghanistan will go and whether the international community will ever again provide significant rehabilitation and development funds for an Afghan national government, the Afghan expatriate community can generate more resources, at zero political cost, for the country's recovery than the international community would be able or willing to do. Peace, national unity and self-determination, as well as the preservation of Afghan culture are possible, if the country's intelligentsia and wealth holders, now mostly residing outside of the country, commit themselves to saving Afghanistan. The need for action is great now and so are the potential rewards for those who have the courage, vision and the patriotic commitment to defend their country, work towards peace and invest in Afghanistan's future.

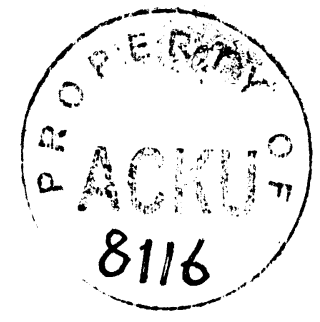

